Research Paper

\title{
Evaluation of Antiviral Activities of Four Local Malaysian Phyllanthus Species against Herpes Simplex Viruses and Possible Antiviral Target
}

\author{
Wee Chee Tan ${ }^{1}$, Indu Bala Jaganath², Rishya Manikam³ and Shamala Devi Sekaran ${ }^{1 凶}$ \\ 1. Department of Medical Microbiology, Faculty of Medicine, University of Malaya, Malaysia. \\ 2. Biotechnology Centre, Malaysia Agricultural Research and Development Institute (MARDI), Serdang, Malaysia. \\ 3. Department of Trauma and Emergency, University Malaya Medical Centre, Malaysia.
}

\begin{abstract}
$\triangle$ Corresponding author: shamalamy@yahoo.com.
(c) Ivyspring International Publisher. This is an open-access article distributed under the terms of the Creative Commons License (http://creativecommons.org/
\end{abstract} licenses/by-nc-nd/3.0/). Reproduction is permitted for personal, noncommercial use, provided that the article is in whole, unmodified, and properly cited.

Received: 2013.06.13; Accepted: 2013.08.19; Published: 2013.10.31

\begin{abstract}
Nucleoside analogues such as acyclovir are effective antiviral drugs against herpes simplex virus infections since its introduction. However, with the emergence of acyclovir-resistant HSV strains particularly in immunocompromised patients, there is a need to develop an alternative antiherpetic drug and plants could be the potential lead. In this study, the antiviral activity of the aqueous extract of four Phyllanthus species were evaluated against herpes simplex virus type-I (HSV-I) and HSV-2 in Vero cells by quantitative PCR. The protein expressions of untreated and treated infected Vero cells were studied by 2D-gel electrophoresis and Western blot. This is the first study that reported the antiviral activity of $P$. watsonii. $P$. urinaria was shown to demonstrate the strongest antiviral activity against $\mathrm{HSV}-\mathrm{I}$ and $\mathrm{HSV}-2$, with $\mathrm{SI}>33.6$. Time-of-addition studies suggested that the extract may act against the early infection stage and the replication stage. Protein expression studies indicated that cellular proteins that are involved in maintaining cytoskeletal structure could be potential target for development of antiviral drugs. Preliminary findings indicated that $P$. urinaria demonstrated potent inhibitory activity against HSV. Hence, further studies such as in vivo evaluation are required for the development of effective antiherpetic drug.
\end{abstract}

Key words: Herpes simplex virus, Phyllanthus, antiviral, cytoskeleton.

\section{Introduction}

Herpes simplex virus can establish lesions at any site of human body and is transmitted via direct contact with infectious secretion $[1,2]$. HSV infection can manifest themselves from an asymptomatic infection to a mucocutaneous infection or life-threatening central nervous system infection [2]. HSV-1 is the most commonly acquired HSV and is the common cause of oral herpes while HSV-2 is the major cause of genital herpes infection [3]. According to the World Health Organization (WHO) report, it was estimated that 536 million people aged 15-49 were living with HSV-2 worldwide in 2003 [4].Furthermore, HSV-2 infection has been reported to be a risk factor in acquiring HIV infection $[5,6]$. Nucleoside analogues such as the acyclovir (ACV) or its subsequent derivatives with better bioavailability such as famciclovir, valacyclovir and penciclovir remain as the mainstay for HSV infection treatment. However, the efficacy of these nucleoside analogues has been compromised by the emergence of ACV-resistant mutant strain in immunocompromised patients such as the organ transplant patient or patient with AIDS [7-9]. Therefore, there is an urgent need for the discovery or development of novel alternative compound with an alternate mechanism of action [10-12].

Medicinal plants have been traditionally used for 
the treatment of ailments [13]. With the advancement of isolation techniques and the emergence of drug resistance mutant strain among the microbes, investigations around the world are attempting to develop novel therapeutic compounds from the medicinal plants. Phyllanthus is the genus under the Euphorbiaceae family and is widely distributed in most tropical and subtropical regions [14, 15]. It has been traditionally used to reduce fever and to treat jaundice and liver diseases [16]. Phyllanthus niruri was first shown to inhibit the hepatitis B virus (HBV) and woodchuck hepatitis virus (WHV) both in vitro and in vivo by Venkateswaran et al [17]. Antiviral testing was carried out using different members of the Phyllanthus family and various species members such as the $P$. amarus, $P$. niruri, $P$. urinaria and $P$. orbicularis have reported to demonstrate potential inhibitory effect against broad spectrum of viruses, such as the hepatitis B virus (HBV), hepatitis $\mathrm{C}$ virus (HCV), human immunodeficiency virus (HIV) and herpes simplex virus (HSV) [18-20]. Apart from the reported antiviral activities, other reported activities include anti-cancer [21, 22], hepatoprotective [23], lipid lowering [24] and blood glucose lowering activity [25], suggesting the broad spectrum activities in this plant species and as a potential drug discovery candidate.

Although $P$. amarus and $P$. niruri have been demonstrated to possess inhibitory action against HBV and HIV, their inhibitory effect was not studied against HSV. Acetone, methanol and ethanolic extract of $P$. urinaria and phytochemicals isolated from these extracts have been shown to inhibit both HSV-1 and HSV-2 in vitro [26, 27]. Hence, our study aimed to determine the antiviral activities of four Phyllanthus species, $P$. amarus, $P$. niruri, $P$. urinaria and $P$. watsonii that are locally found in Malaysia against HSV-1 and HSV-2 in vitro and to study the proteome changes in Vero cells in response to virus infection and extract treatment.

\section{Materials and methods}

\section{Preparation of aqueous plant extracts}

The aqueous extracts of four Phyllanthus species (P. amarus, P. niruri, P. urinaria and P. watsonii) were kindly prepared and provided by the Biotechnology Centre, MARDI, Malaysia. The extracts were prepared as previously described [21, 22]. The four plant species were grown in MARDI under semi-controlled environment. Briefly, freshly harvested plants were washed and dried in room temperature prior freeze-drying. The dried plant samples were then soaked with ultra-pure water and homogenized with extraction buffer. The supernatants were collected after three (3) rounds of extraction. The samples were stored at $-20^{\circ} \mathrm{C}$ until further use. The extracts were weighted and dissolved in sterile PBS solution to reach a final concentration of $10 \mathrm{mg} / \mathrm{mL}$. It was aliquoted into sterile $1.5 \mathrm{~mL}$ tubes and stored at $-20^{\circ} \mathrm{C}$ until further use. Fresh extract solution was thawed and used for every experiment to ensure the activity and the stability of the extracts.

\section{Cells and viruses}

African green monkey kidney Vero cells (ATCC CCL-81) was purchased from the American Type Culture Collection (ATCC). Vero cells were propagated and maintained in Dulbecco's Modified Eagle Medium (DMEM) (Hyclone, USA), supplemented with $5 \%$ heat inactivated fetal bovine serum (FBS) in humidified $37^{\circ} \mathrm{C}, 5 \% \mathrm{CO} 2$ incubator. Clinical isolated HSV-1 and HSV-2 were obtained from Dr. Shamala Devi's laboratory, Department of Medical Microbiology, University of Malaya and propagated in Vero cells. The virus titer was determined by plaque assay as described by [28] with slight modification and was expressed as plaque forming units per $\mathrm{mL}(\mathrm{PFU} / \mathrm{mL}$ ). The virus stocks were stored in $-80^{\circ} \mathrm{C}$ until further use.

\section{Cytotoxicity testing}

The cytotoxic effect of the aqueous extracts of Vero cells was determined by using the CellTiter $96 \AA$ AQueous Non-Radioactive Cell Proliferation Assay kit (Promega, USA) according to the manufacturer's instructions. Vero cells were seeded onto 96-well culture plates at cell density of $1 \times 10^{4}$ cells per well and allowed for overnight incubation for cell attachment. Serial dilution of aqueous extracts were prepared in DMEM and added into each well to reach a final concentration of $62.5,125,250$ and $500 \mu \mathrm{g} / \mathrm{mL}$ respectively. The plates were incubated in $37^{\circ} \mathrm{C}, 5 \%$ $\mathrm{CO}_{2}$ for 72 hours. After 72 hours incubation, the 3-(4,5-dimethylthiazol-2-yl)-5-(3-carboxymethoxyphe nyl)-2-(4-sulfophenyl)-2H-tetrazolium/phenazine methosulfate (MTS/PMS) solution was added into each well and incubated for one hour in dark at $37^{\circ} \mathrm{C}$. The absorbance was measured using the GloMax Multi Detection System (Promega, USA) at 490nm with reference wavelength of $750 \mathrm{~nm}$. The maximum nontoxic dose (MNTD) and the 50\% cytotoxic concentration $\left(\mathrm{CC}_{50}\right)$ of each extract were determined from the dose-response curve and used in subsequent experiments.

\section{Antiviral assay}

Vero cells were seeded onto 24-well culture plates at cell density of $5 \times 10^{4}$ cells per well and allowed for overnight incubation for cell attachment. Vero cells were infected with HSV-1 and HSV-2 at MOI of 0.05 except for the cell control. Extracts were 
added into each designated well at 3 hours before infection (pre-treatment), 0 hours after infection (simultaneous treatment) and 3 hours after infection (post-treatment) to reach a final concentration of $100 \mu \mathrm{g} / \mathrm{mL}$. The cells were rinsed twice with PBS to remove the extracts and any unbound virus during pre- and post-treatment respectively, before virus and extract was added. The plates were incubated in $37^{\circ} \mathrm{C}$, $5 \% \mathrm{CO}_{2}$ for 24,48 and 72 hours respectively. The antiviral effect of the extracts was also tested at 12.5, 50 and $100 \mu \mathrm{g} / \mathrm{mL}$ respectively at 72 hours with simultaneous treatment approach. The plates were subjected to two (2) freeze-thaw cycle at the end of incubation and the supernatants were collected and stored at $-80^{\circ} \mathrm{C}$ until further analysis.

\section{Quantitative real-time polymerase chain re- action assay}

Quantitative real-time polymerase chain reaction (qPCR) assay was used to determine the HSV viral load. The HSV viral DNA was extracted from the supernatant by using the Accuprep Genomic DNA extraction kit (Bioneer, South Korea) according to the manufacturer's protocol and the extracted DNA was stored at $-80^{\circ} \mathrm{C}$ until analysis. An in-house qPCR utilizing SYBR green dye (Biorad, USA) with primers differentiating HSV-1 and HSV-2 were developed. The forward primer sequence for HSV-1 is 5 '-TGGGACACATGCCTTCTTGG while the reverse sequence is $5^{\prime}$-ACCCTTAGTCAGACTCTGTTAC TTACCC, with amplicon size of $147 \mathrm{bp}$. The forward primer sequence for HSV-2 is 5'-GTACAGACCTTCGGAGG while the reverse primer sequence is $5^{\prime}$-CGCTTCATCATGGGC, with amplicon size of $227 \mathrm{bp}$. The assay was performed using the Bio-rad CFX 96 under the following conditions: 15 min activation at $95^{\circ} \mathrm{C}$, followed by 35 cycles of $30 \mathrm{~s}$ at $95^{\circ} \mathrm{C}, 30 \mathrm{~s}$ at $60^{\circ} \mathrm{C}$ and $1 \mathrm{~min}$ at $72^{\circ} \mathrm{C}$ and final elongation at $72^{\circ} \mathrm{C}$ for $10 \mathrm{~min}$. Standard curves were prepared by qPCR using serial dilution of known copies number of purified amplification product for both HSV-1 and HSV-2. The copy number of the samples was calculated from the standard curves. Percentage of reduction was defined as [copy no of infected-copy number of treated]/[copy number of infected] $\times 100$ and the half inhibitory concentration $\left(\mathrm{IC}_{50}\right)$ was determined from the dose response curve. The selective index (SI) value $\left(\mathrm{SI}=\mathrm{CC}_{50} / \mathrm{IC}_{50}\right)$ of each extract was calculated and the extract showing the highest SI value was selected for the 2D-GE analysis.

\section{Plaque reduction assay}

The inhibitory effect of the aqueous extract of Phyllanthus species on HSV infection was also determined by plaque reduction assay as described by
Cheng, Yang [29]. Vero cells were seeded onto 24-well culture plates at cell density of $2 \times 10^{5}$ cells per well and incubated overnight. The medium was discarded and the cell monolayer was infected with 100pfu of HSV-1 or HSV-2 in the absence or presence of the extracts at $50 \mu \mathrm{g} / \mathrm{mL}$ and $100 \mu \mathrm{g} / \mathrm{mL}$ respectively and incubated for one hour for virus adsorption. The cell monolayer was then overlaid with overlay medium containing $1 \%$ methylcellulose and further incubated at $37^{\circ} \mathrm{C}, 5 \% \mathrm{CO}_{2}$ for 3 days. The overlay medium was discarded and the plate was rinsed gently with PBS before stained with $0.1 \%$ naphthalene blue black and the virus titre was determined.

\section{Sample preparation for two-dimensional gel analysis}

Vero cells were seeded onto T-25 cell culture flasks at cell density of $7.5 \times 10^{6}$ cells per flask and allowed for cell attachment overnight. Vero cells were mock-infected (designated $\mathrm{CO}$ ), treated with extract (designated EO), infected with HSV-1 and HSV-2 (designated V1 and $\mathrm{V} 2$ respectively) respectively or infected and treated with $100 \mu \mathrm{g} / \mathrm{mL}$ of extract (designated EV1 and EV2 respectively). The flasks were incubated in $37^{\circ} \mathrm{C}, 5 \% \mathrm{CO}_{2}$ for 72 hours. The cells were trypsinized, washed twice with PBS, pelleted and resuspended in $200 \mu \mathrm{L}$ of lysis buffer (7M urea, $2 \mathrm{M}$ thiourea, 2\% CHAPS, 2\% IPG Buffer pH 3-11NL (GE, Sweden), and 40mM DTT) and incubated at room temperature for 30 minutes with occasional vortexing to ensure complete lysis. The lysate was then centrifuged at $14,000 \mathrm{rpm}$ for 15 minutes at $4^{\circ} \mathrm{C}$ and the supernatant was aliquoted and stored at $-80^{\circ} \mathrm{C}$. Proteins were precipitated by mixing the supernatants with cold acetone, four times the volume of the supernatant and stored at $-20^{\circ} \mathrm{C}$ for at least 2 hour. The suspension was then centrifuged at $4^{\circ} \mathrm{C}, 14,000 \mathrm{rpm}$ for 15 minutes to remove the acetone and the protein pellet was air-dried. The protein pellet was resuspended in the sample rehydration solution (7M urea, 2M thiourea, 4\% CHAPS, 2\% IPG buffer range $\mathrm{pH}$ 3-11NL (GE, Sweden)). The protein concentration of the sample was determined using the 2D-Quant Kit (GE, Sweden) according to the manufacturer's protocol.

\section{Two dimensional gel electrophoresis analysis}

The samples were made up to $250 \mu \mathrm{L}$ with rehydration solution (7M urea, 2M thiourea, 2\% CHAPS, $0.5 \%$ IPG buffer pH3-11NL (GE, Sweden), 0.002\% bromophenol blue) containing $500 \mu \mathrm{g}$ protein. $13 \mathrm{~cm}$ IPG strip with pH3-10NL (GE, Sweden) was rehydrated overnight with the samples. Isoelectric focusing was carried out for total $17.0 \mathrm{kVh}$. Upon completion, the strips were stored in a clean glass tube and 
kept at $-80^{\circ} \mathrm{C}$ until use or was equilibrated in equilibration solution $(6 \mathrm{M}$ urea, $75 \mathrm{mM}$ Tris- $\mathrm{HCl}(\mathrm{pH} 8.8)$, $29.3 \%$ glycerol, $2 \%$ SDS and $0.002 \%$ bromophenol blue) containing $100 \mathrm{mg}$ DTT per $10 \mathrm{~mL}$ for 15 minutes and $250 \mathrm{mg}$ iodoacetamide per $10 \mathrm{~mL}$ for 15 minutes. Proteins were separated by $12.5 \%$ SDS-PAGE gels using $15 \mathrm{~mA}$ per gel for 30 minutes and $30 \mathrm{~mA}$ per gel for 2 hours. Following electrophoresis, the gels were fixed in $45 \% \mathrm{v} / \mathrm{v}$ ethanol and $10 \% \mathrm{v} / \mathrm{v}$ acetic acid and stained with hot Commassie blue stain for one hour. The gels were destained in $45 \% \mathrm{v} / \mathrm{v}$ ethanol and $10 \%$ $\mathrm{v} / \mathrm{v}$ acetic acid and scanned with Image Scanner II (Amersham Bioscience, UK). Scanned images were analysed with basic version PD Quest 2.0 (Biorad, USA). Gels from mock, HSV-1 infected, HSV-2 infected, treated HSV-1 and treated HSV-2 were compared respectively. Differentially expressed spots were excised from the gels and subjected to in-gel trypsin digestion according to the protocol.

\section{In-gel trypsin digestion and mass spectrometry analysis}

The excised gel spots were destained with $50 \%$ acetonitrile in $50 \mathrm{mM}$ ammonium bicarbonate until the gel spots became clear. Reduction of the gel spots was carried out with $10 \mathrm{mM}$ DTT in $100 \mathrm{mM}$ ammonium bicarbonate for $30 \mathrm{~min}$ at $60^{\circ} \mathrm{C}$, followed by alkylation with $55 \mathrm{mM}$ iodoacetamide in $100 \mathrm{mM}$ ammonium bicarbonate for $20 \mathrm{~min}$ in dark. The gel spots were washed three times with $50 \%$ acetonitrile in $100 \mathrm{mM}$ ammonium bicarbonate before dehydrated with 100\% acetonitrile and vacuum dried in speed vacuum. Trypsin digestion was then carried out on the gel spots by incubating with 6ng/uL Trypsin Gold (Promega, USA) in $50 \mathrm{mM}$ ammonium bicarbonate overnight at $37^{\circ} \mathrm{C} .50 \%$ acetonitrile was added and the liquid was transferred to a new tube. 100\% acetonitrile was added into the gel spots and the liquid was transferred to the previous new tube. The liquid was completely dried using the speed vacuum at low speed and stored at $-20^{\circ} \mathrm{C}$. The samples were re-constituted with $0.1 \%$ formic acid and desalted by using C18 ZipTip (Millipore, USA) according to manufacturer's protocol and mix with matrix at an equal ratio before spotted on the MALDI plate. The MALDI plate was then analyzed by using 4800 Plus MALD-TOF/TOF Analyzer (AB Sciex, USA). Raw mass spectra were processed and were searched against Swiss-Prot and NCBInr using MASCOT servers (Matrix Science, UK). Searches were restricted to Primates and Viruses taxonomies respectively.

\section{Antibodies and western blot analysis}

Anti-HSV1 antibody was obtained from a known positive HSV-1 infected donor (consent obtained) and was used at 1/200 dilution. HRP conjugated anti-human IgG was used at 1/1000. HRP-conjugated anti-HSV-2 antibody (Cat no: ab19989) was purchased from Abcam (Cambridge, UK) and used at 1/500 dilution. Protein samples from the two-dimensional gel electrophoresis were used for the Western blot analysis. Western blot was carried out as described by [30] with slight modifications. $50 \mu \mathrm{g}$ of proteins were loaded into each well and were resolved using $12.5 \%$ SDS-PAGE gels at 100V for 1.5 hour. The resolved proteins were transferred onto nitrocellulose membrane (Cat no: RPN3032D, GE, Sweden) at 200mA for one hour. Protein transfer was determined by staining the membrane with Ponceau S stain. The membrane was blocked with 5\% skim milk for one hour, followed by incubation with the primary antibody for overnight. The membrane was washed three times in PBS before incubated with the secondary antibody for 2 hours. 4-chloro-1-napthol was used as the substrate for detection of band of interest. The membrane was scanned and the band intensity was analysed using ImageJ software.

\section{Results}

\section{Cytotoxicity testing}

In order to determine the cytotoxic effect of the four Phyllanthus extracts before subsequent assays, the maximal non toxic dose (MNTD) and the half-maximal cytotoxic concentration $\left(\mathrm{CC}_{50}\right)$ of the four aqueous Phyllanthus extracts, P. amarus, P. niruri, $P$. urinaria and $P$. watsonii were determined on Vero cells by using the conventional MTS assay. Table 1 summarizes the MNTD and the $\mathrm{CC}_{50}$ values for the four Phyllanthus aqueous extracts on Vero cells. Among the four species, $P$. watsonii demonstrated the strongest cytotoxic effect, followed by P. urinaria, $P$. amarus and $P$. niruri. On the contrary, $P$. amarus and $P$. niruri demonstrated higher MNTD values compared to $P$. urinaria and $P$. watsonii. The percentage of cell viability was found to be $90 \%$ at $100 \mu \mathrm{g} / \mathrm{mL}$ for all the extracts. The anti-HSV activity was therefore determined at concentration of $100 \mu \mathrm{g} / \mathrm{mL}$ or lower for the four Phyllanthus extracts.

\section{Antiviral assay}

The dose-response activity of the four extracts against HSV-1 and HSV-2 were determined by using quantitative real-time PCR approach. The extract and the virus were added simultaneously at 12.5, 50 and $100 \mu \mathrm{g} / \mathrm{mL}$ respectively and incubated for 72 hours before the viral copies number were determined.. The half-maximal inhibitory concentration $\left(\mathrm{IC}_{50}\right)$ was determined and the selective index (SI) of each extract against HSV-1 and HSV-2 were tabulated in Table 1. The antiviral activity of the extracts against HSV-1 
and HSV-2 were confirmed by conventional plaque reduction assay (Figure 1). Similar findings were observed, indicating the extracts inhibited the viral replication in vitro. Among the four Phyllanthus species,
P. urinaria was found to have the highest SI value against both HSV-1 and HSV-2, hence it was chosen for the subsequent 2D-GE analysis and Western blot assay.

Table I. The $\mathrm{CC}_{50}, \mathrm{IC}_{50}$ and $\mathrm{SI}$ of the Phyllanthus extracts against HSV-I and HSV-2.

\begin{tabular}{|c|c|c|c|c|c|c|}
\hline Phyllanthus species & MNTD & $\mathrm{CC}_{50}(\mu \mathrm{g} / \mathrm{mL})$ & $\mathrm{IC}_{50}(\mu \mathrm{g} / \mathrm{r}$ & & $S I$ & \\
\hline & & & HSV-1 & HSV-2 & HSV-1 & HSV-2 \\
\hline P. amarus & $<125$ & $\geq 500$ & $15.5 \pm 3.7$ & $16.2 \pm 5.2$ & 32.2 & 30.8 \\
\hline P. niruri & $<125$ & $\geq 500$ & $37.5 \pm 8.2$ & $39.5 \pm 9.4$ & 13.3 & 12.7 \\
\hline P. urinaria & $<100$ & $420.3 \pm 8.4$ & $<12.5$ & $<12.5$ & $>33.6$ & $>33.6$ \\
\hline P. watsonii & $<100$ & $300.0 \pm 4.5$ & $11.9 \pm 6.8$ & $<12.5$ & 25.3 & $>24.0$ \\
\hline
\end{tabular}
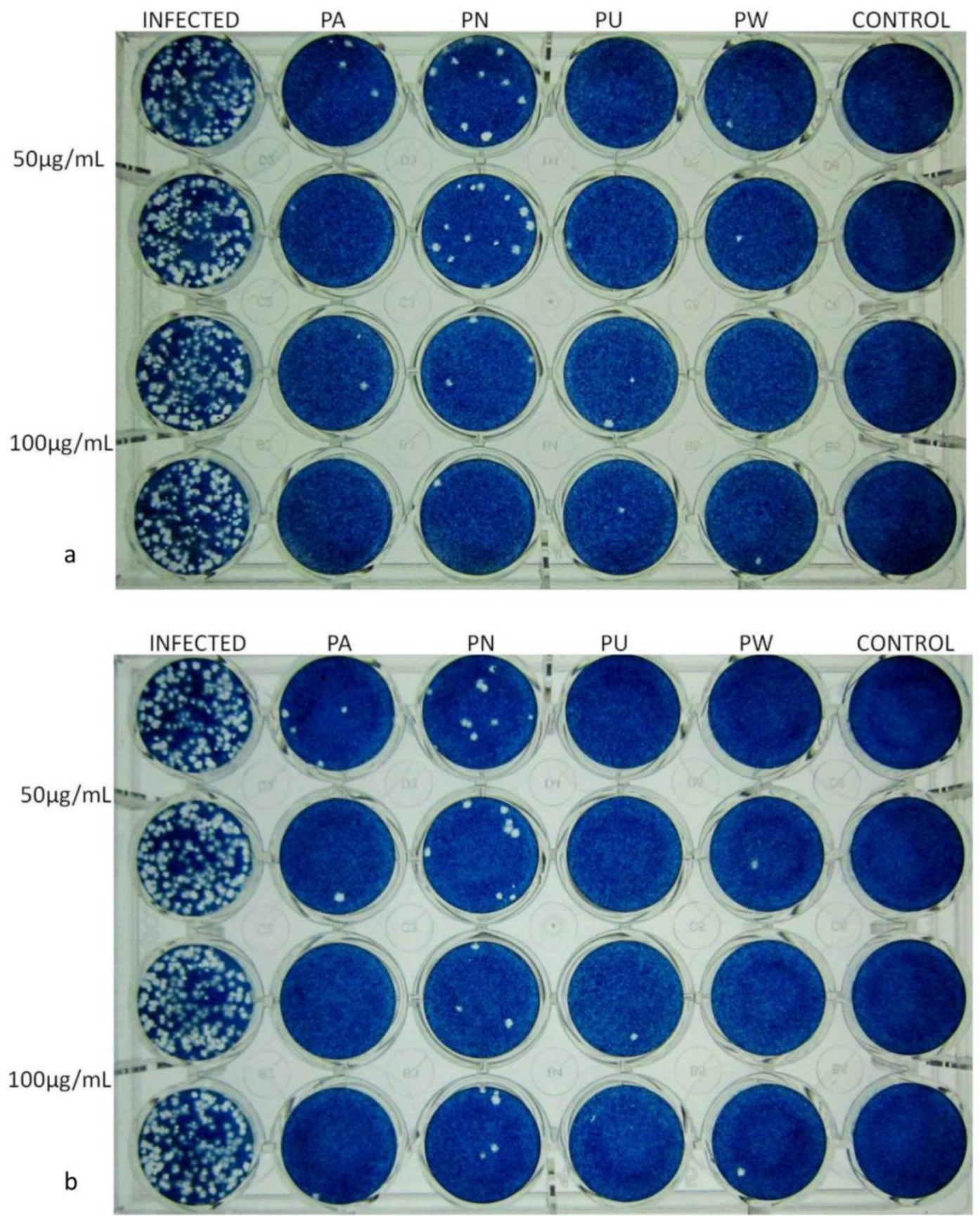

Fig I. The dose-dependent antiviral activity of aqueous Phyllanthus extracts against HSV-I and HSV-2 by plaque reduction assay. (a) The representative plaque reduction assay for HSV-I. (b) The representative plaque reduction assay for HSV-2. Abbreviation: Infected: virus infected Vero cells; PA: P. amarus treated infected cells; PN: P. niruri treated infected cells; PU: P. urinaria treated infected cells; PW: P. watsonii treated infected cells. 
In order to study at which stage the extracts exerting their effect against the viruses, the antiviral activity of the four Phyllanthus species against HSV-1 and HSV-2 were also determined at pre-treatment, simultaneous treatment and post-treatment respectively by using quantitative real time PCR approach. Figure 1 and Figure 2 summarized the antiviral activity of $100 \mu \mathrm{g} / \mathrm{mL}$ of the four Phyllanthus extracts against HSV-1 and HSV-2 respectively by pre-, simultaneous and post-treatment at 24, 48 and 72 hours.
At $100 \mu \mathrm{g} / \mathrm{mL}$, all four aqueous extracts were found to be most effective in inhibiting both HSV-1 and HSV-2 viral replication by simultaneous treatment and post-treatment but less effective for pre-treatment. This suggested the extracts might affect the events in the early infection such as viral binding and viral entry as well as the viral replication. Furthermore, the four aqueous extracts were found to demonstrate more potent inhibitory activity against HSV-2 than HSV-1.
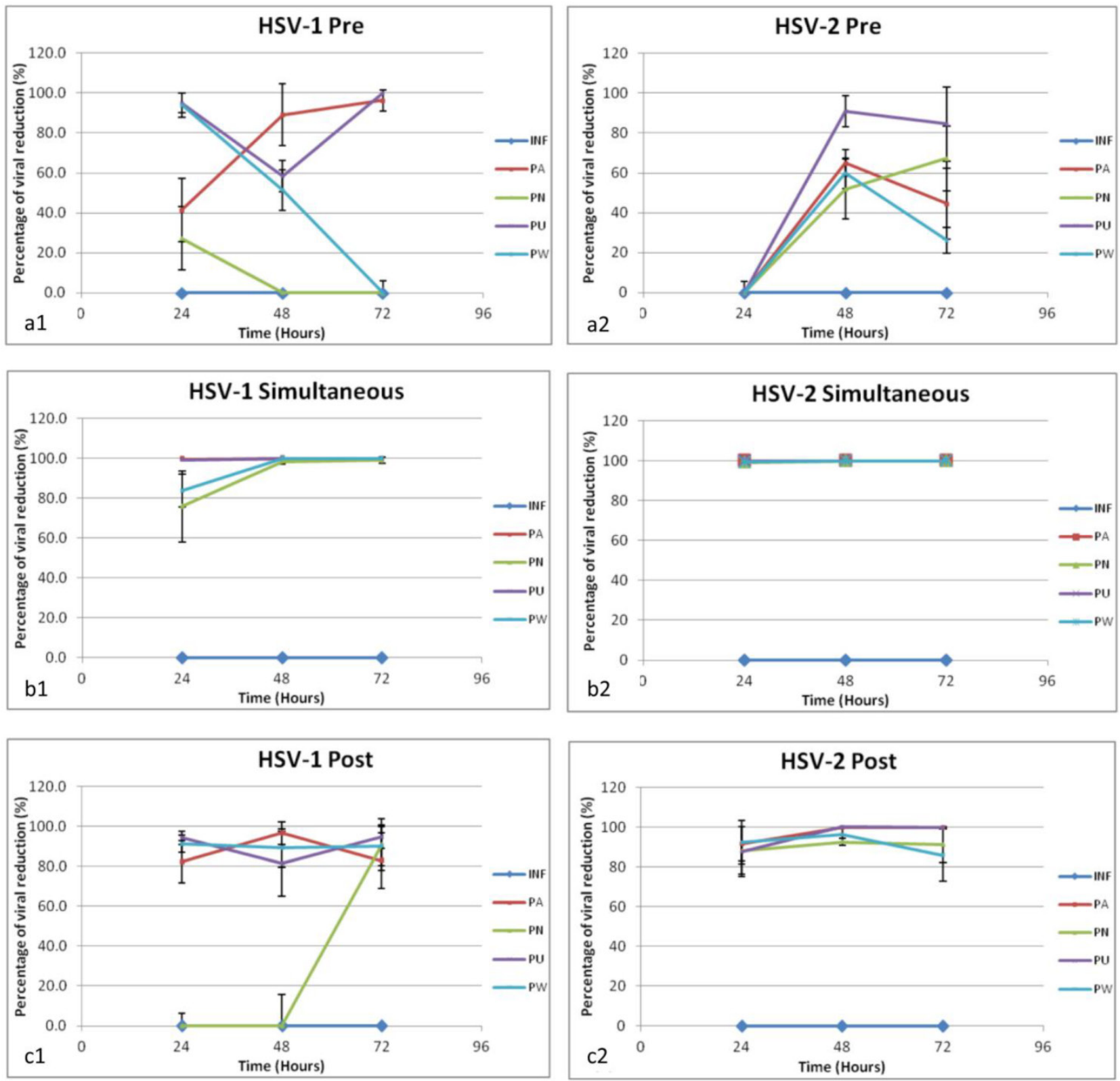

Fig 2. Time-of-addition study of HSV-I and HSV-2. The time-dependent curves of the antiviral activity of Aqueous Phyllanthus extracts against HSV-I and HSV-2 respectively at (al, a2) pre-treatment; (bl, b2) simultaneous treatment and (cl, c2) post-treatment. Results are expressed as the percentage of viral copy number reduction compared to the untreated control. Each value is the mean $\pm S$.D. of three independent experiment. Abbreviation: INF: infected control; PA: $P$. amarus treated; PN: P. niruri treated; PU: P. urinaria treated; PW: P. watsonii treated. 


\section{Two dimensional gel electrophoresis and mass spectrometry}

In order to understand how the HSV infection and the extract treatment affected the proteome of the host cells, two dimensional gel electrophoresis followed by mass spectrometry protein identification was carried out (Figure 3 and 4). 54 spots and 52 spots

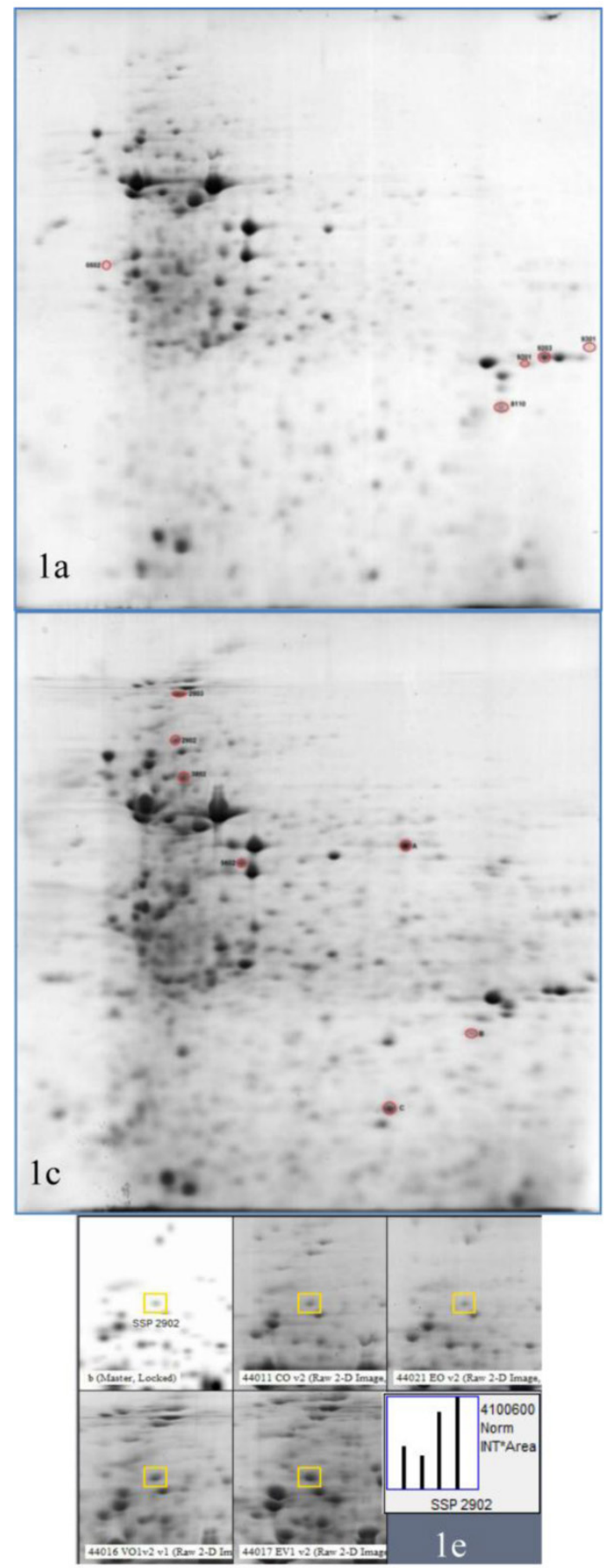

were found to be differentially expressed in response to HSV-1 and HSV-2 infection in Vero cells respectively. Simultaneous treatment of $P$. urinaria extract was found to correct the change back to normal expression level as compared to the uninfected and the extract-treated cells.

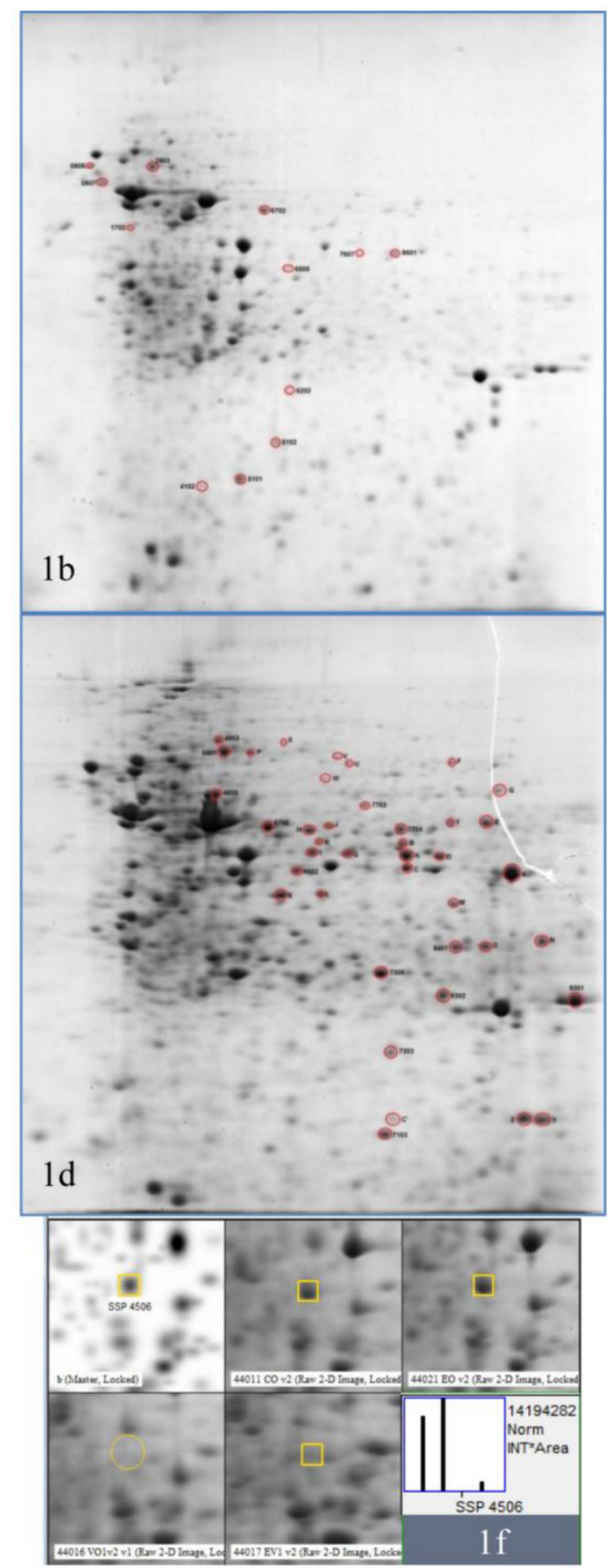

Fig 3. 2DE gels of Vero cell lysate in response to HSV-I infection and $P$. urinaria $(\mathbf{I} 00 \mu \mathrm{g} / \mathrm{mL})$ treatment or both. (Ia) is the untreated uninfected Vero cell, (Ib) is the P. urinaria treated uninfected, (Ic) is the HSV-I infected untreated and (Id) is the P. urinaria treated HSV-I infected cell. (Ie) and (If) is the representative of the spot analysis whereby (Ie) and (If) were identified as alpha-actinin-I and cytoplasmic actin and respectively. 

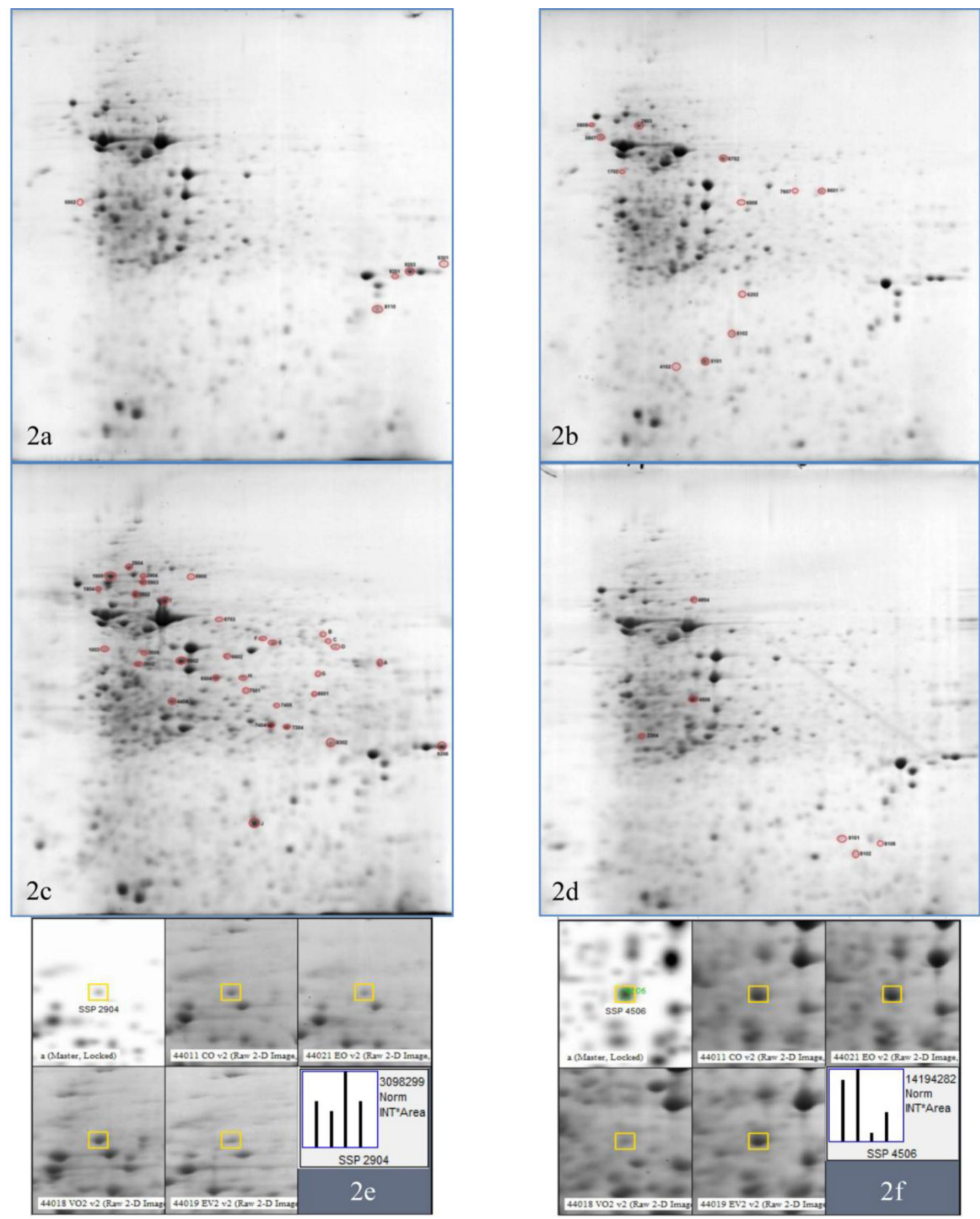

Fig 4. 2DE gels of Vero cell lysate in response to HSV-2 infection and $P$. urinaria $(100 \mu g / \mathbf{m L})$ treatment or both. (2a) is the untreated uninfected Vero cell, $(2 \mathrm{~b})$ is the P. urinaria treated uninfected, $(2 \mathrm{c})$ is the HSV-2 infected untreated and $(2 \mathrm{~d})$ is the P. urinaria treated HSV-2 infected cell. (2e) and (2f) is the representative of the spot analysis whereby (2e) and (2f) were identified as alpha-actinin-I and cytoplasmic actin respectively.

A total of 20 proteins were identified by mass spectrometry protein identification based on the Mascot score algorithm. The identified proteins were tabulated in Table 2 and Table 3 respectively. The identified proteins were found to involve primarily in the cellular cytoskeletal maintenance (8), metabolism (7), protein folding (2) and heat shock proteins (2). One viral protein, the major DNA binding protein
(ICP8) of HSV-1 was identified.

\section{Western blot analysis}

The HSV viral proteins expression was studied by performing an immunoprecipitation Western blot (Figure 5). Viral proteins including viral glycoprotein B (gB) [100kDa], glycoprotein D (gD) [40-43kDa], VP16 (also known as a-TIF) [50kDa] and VP22 
[38kDa] which played important role in determining efficient viral attachment and entry into the cells were identified based on their respective molecular weight. It was found that simultaneous treatment of $P$. uri-

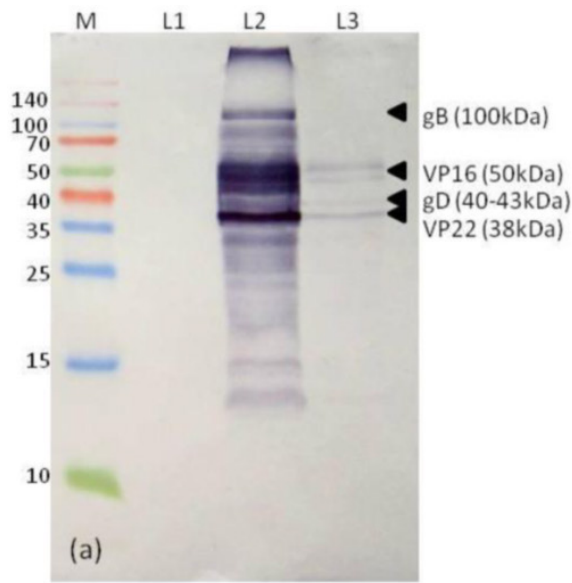

naria at $100 \mu \mathrm{g} / \mathrm{mL}$ reduced the expression of the four viral proteins by more than $90 \%$. Meanwhile, it was shown that the extract treatment completely inhibited the HSV-2 viral proteins expression.

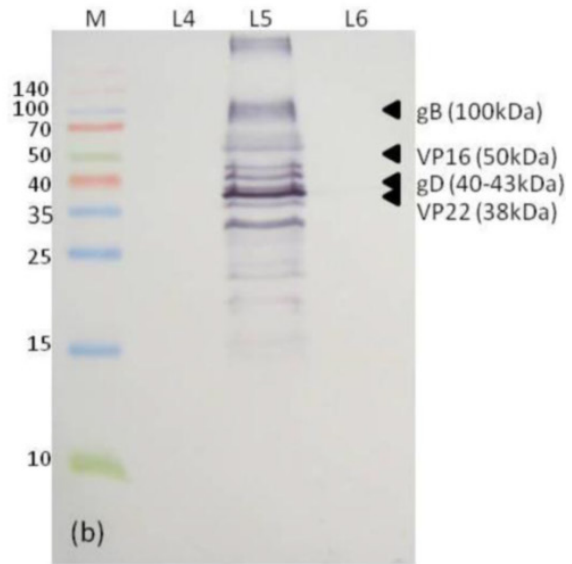

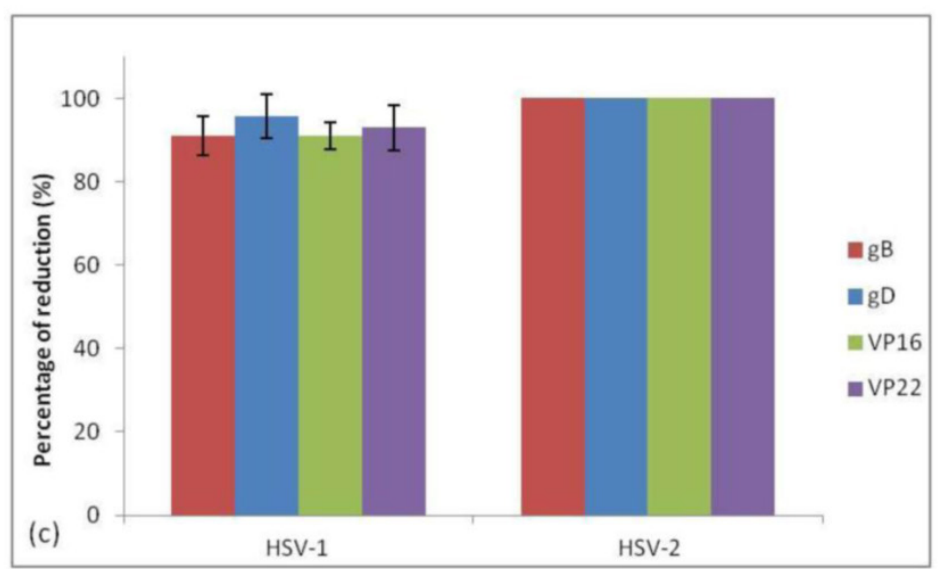

Fig 5. Western blot of HSV-I and HSV-2 viral proteins expression in the with or without extract treatment. (a) Immunoblot for HSV-I viral protein expression. (b) Immunoblot for HSV-2 viral protein expressions. (c) Histogram showing the percentage of reduction of HSV-I and HSV-2 viral protein expression in the presence of extract treatment. Abbreviation: M: protein marker; LI: uninfected cell; L2: HSV-I infected cell; L3: P. urinaria-treated HSV-I infected cell; L4: uninfected cell; L5: HSV-2 infected cell; L6: P. urinaria-treated HSV-2 infected cell.

Table 2. Proteins with differential expression identified by mass spectrometry for HSV-I set.

\begin{tabular}{|c|c|c|c|c|c|c|}
\hline \multirow[t]{2}{*}{ ID } & \multicolumn{4}{|c|}{ Expression level } & \multirow[t]{2}{*}{ Protein name } & \multirow[t]{2}{*}{ MASCOT score } \\
\hline & $\mathrm{CO} 1$ & EO1 & VO1 & EV1 & & \\
\hline \multicolumn{7}{|c|}{ Cytoskeletal proteins } \\
\hline 2902 & 1.0 & -2.0 & 1.8 & 2.2 & alpha-actinin I & 347 \\
\hline 4506 & 1.0 & 1.0 & 0.0 & -10.0 & actin, cytoplasmic 1 & 358 \\
\hline Q & 0.0 & 0.0 & 0.0 & 1.0 & keratin, type II cytoskeletal & 104 \\
\hline $\mathrm{M}$ & 0.0 & 0.0 & 0.0 & 1.0 & annexin A2 & 135 \\
\hline \multicolumn{7}{|c|}{ Metabolism } \\
\hline I & 0.0 & 0.0 & 0.0 & 1.0 & alpha-enolase & 100 \\
\hline $\mathrm{F}$ & 0.0 & 0.0 & 0.0 & 1.0 & glucose-6-phosphate-1 dehydrogenase & 108 \\
\hline 3802 & 1.0 & -1.7 & 1.2 & 1.0 & ATP synthase subunit beta, mitochondrial & 454 \\
\hline 7305 & 1.0 & 1.0 & 2.5 & 5.0 & triosephosphate isomerase & 101 \\
\hline \multicolumn{7}{|c|}{ Protein folding } \\
\hline $\mathrm{V}$ & 0.0 & 0.0 & 0.0 & 1.0 & protein disulfide isomerase $\mathrm{A} 3$ & 71 \\
\hline \multicolumn{7}{|c|}{ Heat shock proteins } \\
\hline 2502 & 1.0 & 1.3 & 3.3 & 3.3 & $60 \mathrm{kDa}$ heat shock protein, mitochondrial & 136 \\
\hline 8401 & 1.0 & 2.5 & 3.8 & 12.5 & heat shock protein $70 \mathrm{kDa}$ & 193 \\
\hline \multicolumn{7}{|c|}{ Viral proteins } \\
\hline $\mathrm{U}$ & 0.0 & 0.0 & 0.0 & 1.0 & major DNA binding protein (HSV) & 76 \\
\hline
\end{tabular}


Table 3. Proteins with differential expression identified by mass spectrometry for HSV-2 set.

\begin{tabular}{|c|c|c|c|c|c|c|}
\hline \multirow[t]{2}{*}{ ID } & \multicolumn{4}{|c|}{ Expression level } & \multirow[t]{2}{*}{ Protein name } & \multirow[t]{2}{*}{ MASCOT score } \\
\hline & $\mathrm{CO} 2$ & $\mathrm{EO} 2$ & $\mathrm{VO} 2$ & EV2 & & \\
\hline \multicolumn{7}{|c|}{ Cytoskeletal proteins } \\
\hline 2904 & 1.0 & -2.0 & 1.5 & 1.0 & alpha-actinin-1 & 57 \\
\hline 3904 & 1.0 & -1.1 & 2.0 & -2.0 & keratin, type I cytoskeletal & 79 \\
\hline 4404 & 0.0 & 1.0 & 6.3 & 0.8 & keratin, type II cytoskeletal & 88 \\
\hline 4506 & 1.0 & 1.0 & -10.0 & -1.7 & actin, cytoplasmic 1 & 77 \\
\hline \multicolumn{7}{|c|}{ Metabolism } \\
\hline I & 0.0 & 0.0 & 1.0 & 0.0 & alpha-enolase & 100 \\
\hline 7304 & 1.0 & 1.0 & 3.5 & 1.5 & triosephosphate isomerase & 70 \\
\hline 9201 & 1.0 & 2.0 & 0.0 & 1.0 & peroxiredoxin-1 & 99 \\
\hline \multicolumn{7}{|c|}{ Protein folding } \\
\hline 1905 & 1.0 & -2.3 & 1.4 & -3.5 & protein disulfide isomerase & 91 \\
\hline
\end{tabular}

\section{Discussion}

The Phyllanthus genus of the family Phyllanthaceae consists of about $750-800$ species that are widely distributed in the tropical and subtropical region [14]. However, despite the extensive antiviral studies that was carried out on Phyllanthus species, only P. urinaria, P. emblica and P. orbicularis have been tested for their antiviral activities against HSV, whereas other species such as $P$. amarus and $P$. niruri that demonstrate potent antiviral activity against HIV and HBV have not been tested against HSV [20, 26, 31]. Hence this study would be the first preliminary study that determine and compare the anti-HSV activities of the four Phyllanthus species, namely P. amarus, $P$. niruri, $P$. urinaria and $P$. watsonii that can be locally found in Malaysia by using quantitative real-time PCR.

Our findings indicated that the extracts were most effective when added either simultaneously with the initiation of virus infection or post infection but not when given pre-infection, suggesting the extract may act at the early stage of infection such as during viral attachment and entry as well as viral replication. Among the four Phyllanthus species, $P$. urinaria demonstrated the strongest antiviral activities against HSV-1 and HSV-2, with a SI value of more than 33.6, followed by $P$. watsonii, $P$. amarus and $P$. niruri. This study was also the first antiviral study that determined the antiviral activities of $P$. watsonii, which can be found endemically in the Peninsular Malaysia. Numerous studies have highlighted the potential anticancer activities of $P$. watsonii against a variety of human cancer cell lines, such as prostate cancer, skin melanoma, breast cancer and lung cancer cell lines [21, 22], but there is no antiviral study that determine the antiviral activities of $P$. watsonii till date.

Reviews have suggested that the phytochemicals present in the prepared extracts contributed to the antiviral activities of the plants $[13,18,19,32]$. Previous studies by Lee, Jaganath [22] and Tang, Jaganath [21] have identified the presence of several polyphenols in the extracts prepared from Phyllanthus including geraniin, rutin, gallic acid, caffeolquinic acid, corilagen, galloylglucopyronoside, digalloylglucopyronoside, trigalloylglucopyronoside, quercetin rhamnoside and quercetin glucoside. It was found that trigalloylglucopyronoside only present in P. urinaria while quercetin rhamnoside only present in $P$. urinaria and $P$. watsonii. The presence of trigalloylglucopyronoside in P. urinaria might have contributed to the stronger antiviral activity observed. It is possible that the chemistry and the amount of these polyphenols have synergistic effect towards the antiviral activities observed. Different mode of inhibition was also observed in antiviral study that tested the isolated phytochemicals against HSV-1 and HSV-2, suggesting possible difference in mechanism of inhibition and possible synergistic or antagonistic effect. For instance, geraniin and 1,3,4,6-TODG which were isolated from acetone extract of $P$. urinaria, demonstrated serotype specific inhibition against HSV-1 and HSV-2 respectively [27]. Another pure compound, excoecarianin, isolated from the acetone $P$. urinaria extract selectively inhibited HSV-2 but not HSV-1 with a SI value of 20.0 against HSV-2 infection [29]. Furthermore, it was found to synergize the antiviral effect of acyclovir when combination of excoecarianin and acyclovir was added onto infected Vero cells [29]. Thus, synergism may exist between the phytochemicals in the extracts in which one phytochemical may potentiate or compensate the loss of action of other phytochemicals.

HSV replication cycle takes place in a complicated yet highly regulated manner. Before any viral replication takes place, the virus must be able to attach itself to the host and enter the cells. There are two important HSV viral glycoproteins, namely glycoprotein $\mathrm{B}(\mathrm{gB})$ and glycoprotein $\mathrm{D}(\mathrm{gD})$ that are es- 
sential for facilitating efficient virus entry via the interaction with the host heparan sulphate receptors and associated co-receptors. After gaining entry into the cells, the VP16 (or a-TIF) which is brought in with the virion tegument stimulates the transcription of the immediate early genes [1]. Our findings indicated that the extract treatment inhibited the success of the viral entry process, thereby leads to the lowered expression of $\mathrm{gB}, \mathrm{gD}$ and VP16 observed in the Western blot assay.

After gaining entry, the viral nucleocapsid gets propelled along the microtubule toward the nucleus for DNA replication. In this study, we found that proteins that are involved in maintaining the cellular cytoskeletal integrity such as the cytoplasmic actin was down regulated while the cytoskeletal keratin was found to be up regulated in response to HSV infection as depicted in Figure 6. Similar observation was reported by Antrobus, Grant [33] in which cytoplasmic actin was down regulated in response to HSV-1 infection. The addition of extract treatment was shown to correct the expression level of both cytoplasmic actin and keratin to normal level.

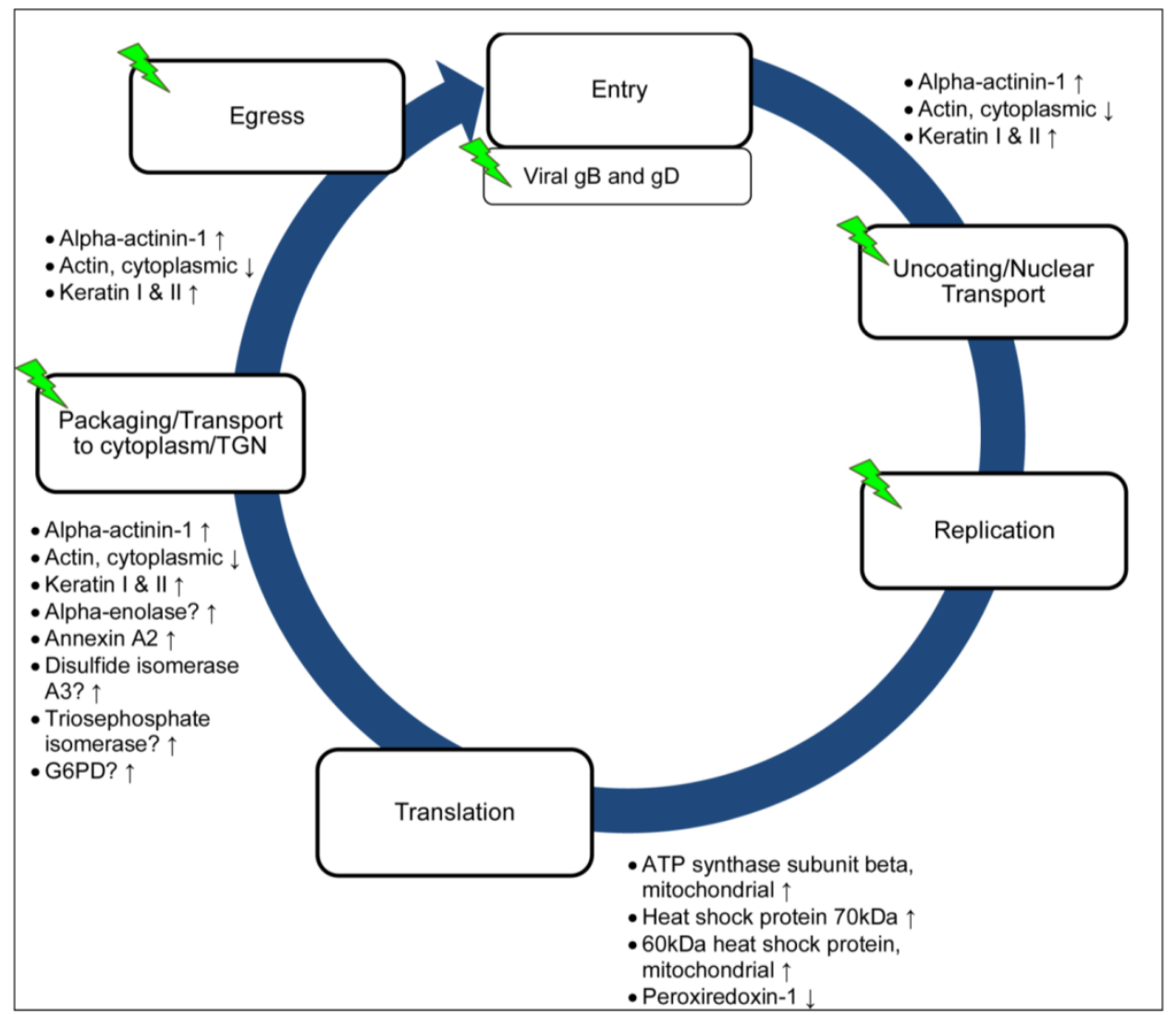

Fig 6. Possible involvement of $P$. urinaria in the life cycle of HSV. The diagram showing the possible involvement of proteins identified in the life cycle of HSV and the arrows indicated the expression level of proteins in response to HSV infection. The green icon represents possible point of inhibition of $P$. urinaria.

In this study, another protein, alpha-actinin-1, which is involved in the maintenance of the cytoskeletal integrity was found to be up regulated in response to the HSV infection. Alpha-actinin-1 is one of the four isoforms of the alpha-actinin, a cytoskeletal protein that can be found ubiquitously in "non-muscle" cell [34]. Alpha-actinin is a multifunctional protein, besides linking the cytoskeleton to various transmembrane proteins, it also regulates the activity of various receptors and the downstream signalling pathways [34]. Alpha-actinin has been demonstrated to be essential for the hepatitis $C$ virus replication [35]. Moreover, alpha-actinin interacts with known regulators of detachment steps of cell migration, suggesting that similar signalling interaction may occurs during virus infection leading to formation of cytopathic effect of infected cells such as rounding up and detachment prior to cell death [36]. There is limited information currently on how and why HSV infection induced the up regulation of alpha-actinin in Vero cells. It is possible that the infection induced the up regulation of the alpha-actinin-1 which then activated the downstream signalling pathway leading to the disruption of the stability of the host cytoskeleton dynamic. The mechanism underlying this observation is currently unclear and it is unknown whether this applicable to other cell types or is unique to Vero cells. The expression level of al- 
pha-actinin-1 was shown to be lowered to normal expression level when $P$. urinaria was added to the HSV-2 infected cells, but did not exhibit any lowering effect on the expression level of alpha-actinin- 1 in HSV-1 infected cells. This could indicate that although both HSV-1 and HSV-2 are two closely related viruses, the viruses may manipulate the cells via different mechanisms and thus the extract may act differently, as observed in the study by Cheng, Yang [29] and Yang, Cheng [26].

The viral replication and the increased expression of the viral proteins as well as the introduction of the extract may induce cellular stress to the host cell and trigger the increased expression of the heat shock proteins (HSPs) such as the heat shock protein $70 \mathrm{kDa}$ and the mitochondrial heat shock protein $60 \mathrm{kDa}$, together with the chaperone proteins including protein disulfide isomerase to respond to the accumulation of unfolded or misfolded viral or host proteins. The expression of host proteins that are involved in the cellular metabolism process such as alpha-enolase was found to be up regulated in response to HSV-1 and HSV-2, whereas peroxiredoxin-1 was down regulated in response to HSV-2 infection. A study by Antrobus, Grant [33] also reported the up regulation of alpha-enolase and it has been demonstrated that HSV-1 infection induced the activation of the glycolytic pathway [37]. It is unknown for now why HSV-2 infection leads to the down regulation of peroxiredoxin-1, but expression of peroxiredoxin-1 has been shown to be protective against RSV infection [38].

Hence, based on the current findings of this study, we could postulate that despite HSV-1 and HSV-2 are two closely related viruses, they manipulate their host in a slightly different manners. The antiviral activities exhibited by $P$. urinaria extract could be due to the multiple action of the extract on the virus, including (1) inhibited the viral entry, thereby down regulates the viral $\mathrm{gB}, \mathrm{gD}$ and VP16 that are essential for viral attachment and entry; (2) inhibits the manipulation of the host actin-cytoskeleton dynamics by the virus; (3) prevents manipulation of the host proteins by the virus. In conclusion, Phyllanthus species emerges as a potential candidate in the development of effective antiviral drugs against HSV-1 and HSV-2, although further in-depth studies are needed to provide an insight into the mechanism involved and the identification of responsible target.

\section{Acknowledgement}

This study was supported by the Malaysian Agriculture and Research Development Institute Grant (53-02-03-1002) and the University of Malaya IPPP student research grant (PS181/2010A and PV053/2011b). We would like to acknowledge the
Medical Biotechnology Laboratory, Faculty of Medicine, University of Malaya for their permission to use the 2D-GE equipment and for providing the mass spectrometry analysis in this study.

\section{Competing Interests}

The authors have declared that no competing interest exists.

\section{References}

1. Roizman B, Knipe DM, Whitley RJ. Herpes Simplex Viruses. In: Knipe DM, Howley PM, editors. Fields Virology, 5th edition. Philadelphia: Lippincott Williams \& Wilkins; 2006;: 2501-601.

2. Fatahzadeh $M$, Schwartz RA. Human herpes simplex infections: Epidemiology, pathogenesis, symptomatology, diagnosis, and management. Journal of the American Academy of Dermatology. 2007; 57: 737-63.

3. Whitley RJ, Roizman B. Herpes simplex virus infections. The Lancet. 2001; 357: 1513-8.

4. Looker KJ, Garnett GP, Schmid GP. An estimate of the global prevalence and incidence of herpes simplex virus type 2 infection. Bulletin of the World Health Organization. 2008; 86: 805-12A.

5. Celum C, Wald A, Lingappa JR, Magaret AS, Wang RS, Mugo N. Acyclovir and Transmission of HIV-1 from Persons Infected with HIV-1 and HSV-2. New England Journal of Medicine. 2010; 362: 427-39.

6. Corey L. Synergistic Copathogens- HIV-1 and HSV-2. New England Journal of Medicine. 2007; 356: 854-6.

7. Morfin F, Thouvenot D. Herpes simplex virus resistance to antiviral drugs. Journal of Clinical Virology. 2003; 26: 29-37.

8. Bacon TH, Levin MJ, Leary JJ, Sarisky RT, Sutton D. Herpes Simplex Virus Resistance to Acyclovir and Penciclovir after Two Decades of Antiviral Therapy. Clinical Microbiology Reviews. 2003; 16: 114-28.

9. Piret J, Boivin G. Resistance of Herpes Simplex Viruses to Nucleoside Analogues: Mechanisms, Prevalence, and Management. Antimicrobial Agents and Chemotherapy. 2011; 55: 459-72.

10. Vilhelmova N, Jacquet R, Quideau S, Stoyanova A, Galabov AS. Three-dimensional analysis of combination effect of ellagitannins and acyclovir on herpes simplex virus type 1 and 2. Antiviral research. 2011; 89: $174-81$.

11. Xiong Hr, Luo J, Hou W, Xiao H, Yang Zq. The effect of emodin, an anthraquinone derivative extracted from the roots of Rheum tanguticum, agaist herpes simplex virus in vitro and in vivo. Journal of Ethnopharmacology. 2011; 133: 718-23.

12. Chen X, Qiao H, Liu T, Yang Z, Xu L, Xu Y, et al. Inhibition of herpes simplex virus infection by oligomeric stilbenoids through ROS generation. Antiviral Research. 2012; 95: 30-6.

13. Mukhtar M, Arshad M, Ahmad M, Pomerantz RJ, Wigdahl B, Parveen Z. Antiviral potentials of medicinal plants. Virus Research. 2008; 131: 111-20.

14. Joseph B, Raj SJ. An Overview: Pharmacognostic Properties of Phyllanthus amarus Linn. International Journal of Pharmacology. 2011; 7: 40-5.

15. Calixto JB, Santos ARS, Filho VC, Yunes RA. A review of the plants of the genus Phyllanthus: Their chemistry, pharmacology, and therapeutic potential. Medical Research Reviews. 1998; 18: 225-58.

16. Unander DW, Webster GL, Blumberg BS. Usage and bioassays in Phyllanthus (Euphorbiaceae). IV. Clustering of antiviral uses and other effects. Journal of Ethnopharmacology. 1995; 45: 1-18.

17. Venkateswaran PS, Millman I, Blumberg BS. Effects of an extract from Phyllanthus niruri on hepatitis B and woodchuck hepatitis viruses: in vitro and in vivo. Proceedings of the National Academy of Sciences. 1987; 84: 274-8.

18. Xiang Yf, Pei Y, Wang Yf. Current status of natural products from plants as anti-herpes simplex virus 1 agents. Virologica Sinica. 2008; 23: 305-14.

19. Khan MTH, Ather A, Thompson KD, Gambari R. Extracts and molecules from medicinal plants against herpes simplex viruses. Antiviral Research. 2005; 67: 107-19.

20. Álvarez ÁL, Dalton KP, Nicieza I, Diñeiro Y, Picinelli A, Melón S, et al. Bioactivity-guided Fractionation of Phyllanthus orbicularis and Identification of the Principal Anti HSV-2 Compounds. Phytotherapy Research. 2012; 26: 1513-20.

21. Tang YQ, Jaganath IB, Sekaran SD. Phyllanthus spp. Induces Selective Growth Inhibition of PC-3 and MeWo Human Cancer Cells through Modulation of Cell Cycle and Induction of Apoptosis. PLoS ONE. 2010; 5: e12644.

22. Lee SH, Jaganath IB, Wang SM, Sekaran SD. Antimetastatic Effects of Phyllanthus on Human Lung (A549) and Breast (MCF-7) Cancer Cell. PLoS ONE. 2011; 6: e20994.

23. Rajeshkumar NV, Kuttan R. Phyllanthus amarus extract administration increases the life span of rats with hepatocellular carcinoma. Journal of Ethnopharmacology. 2000; 73: 215-9.

24. Khanna AK, Rizvi F, Chander R. Lipid lowering activity of Phyllanthus niruri in hyperlipemic rats. Journal of Ethnopharmacology. 2002; 82: 19-22. 
25. Ali H, Houghton PJ, Soumyanath A. a-Amylase inhibitory activity of some Malaysian plants used to treat diabetes; with particular reference to Phyllanthus amarus. Journal of Ethnopharmacology. 2006; 107: 449-55.

26. Yang C-M, Cheng HY, Lin T-C, Chiang LC, Lin CC. Acetone, ethanol and methanol extracts of Phyllanthus urinaria inhibit HSV-2 infection in vitro. Antiviral Research. 2005; 67: 24-30.

27. Yang CM, Cheng HY, Lin TC, Chiang LC, Lin CC. The in vitro activity of geraniin and 1,3,4,6-tetra-O-galloyl- $\beta$-d-glucose isolated from Phyllanthus urinaria against herpes simplex virus type 1 and type 2 infection. Journal of Ethnopharmacology. 2007; 110: 555-8.

28. Chattopadhyay D, Chawla-Sarkar M, Chatterjee T, Dey RS, Bag P, Chakraborti $S$, et al. Recent advancements for the evaluation of anti-viral activities of natural products. New Biotechnology. 2009; 25: 347-68.

29. Cheng HY, Yang CM, Lin TC, Chiang LC, Lin CC Excoecarianin, Isolated from Phyllanthus urinaria Linnea, Inhibits Herpes Simplex Virus Type 2 Infection through Inactivation of Viral Particles. Evidence-Based Complementary and Alternative Medicine. 2011; :259103.

30. Towbin H, Staehelin T, Gordon J. Electrophoretic transfer of proteins from polyacrylamide gels to nitrocellulose sheets: procedure and some applications. Proceedings of the National Academy of Sciences. 1979; 76: 4350-4.

31. Zhong MG, Xiang YF, Qiu XX, Liu Z, Kitazato K, Wang YF. Natural products as a source of anti-herpes simplex virus agents. RSC Advances. 2012. doi:10.1039/c2ra21464d.

32. Naithani R, Huma LC, Holland LE, Louis E H, Shukla D, McCormick DL, et al. Antiviral Activity of Phytochemicals: A Comprehensive Review. Mini Reviews in Medicinal Chemistry. 2008; 8: 1106-33.

33. Antrobus R, Grant K, Gangadharan B, Chittenden D, Everett RD, Zitzmann N, et al. Proteomic analysis of cells in the early stages of herpes simplex virus type-1 infection reveals widespread changes in the host cell proteome. Proteomics. 2009; 9: 3913-27.

34. Oikonomou KG, Zachou K, Dalekos GN. Alpha-actinin: A multidisciplinary protein with important role in B-cell driven autoimmunity. Autoimmunity Reviews. 2011; 10: 389-96.

35. Lan $S$, Wang $H$, Jiang $H$, Mao $H$, Liu $X$, Zhang $X$, et al. Direct interaction between a-actinin and hepatitis C virus NS5B. FESB Letters. 2003; 554: 289-94.

36. Otey CA, Carpen O. a-actinin revisited: A fresh look at an old player. Cell Motility and the Cytoskeleton. 2004; 58: 104-11.

37. Abrantes JL, Alves CM, Costa J, Almeida FCL, Sola-Penna M, Fontes CFL, et al. Herpes simplex type 1 activates glycolysis through engagement of the enzyme 6-phosphofructo-1-kinase (PFK-1). Biochimica et Biophysica Acta (BBA)-Molecular Basis of Disease. 2012; 1822: 1198-206

38. Jamaluddin M, Wiktorowicz JE, Soman KV, Boldogh I, Forbus JD, Spratt H, et al. Role of Peroxiredoxin 1 and Peroxiredoxin 4 in Protection of Respiratory Syncytial Virus-Induced Cysteinyl Oxidation of Nuclear Cytoskeletal Proteins. Journal of Virology. 2010; 84: 9533-45. 